\title{
ERCC1 mRNA levels can predict the response to cisplatin-based concurrent chemoradiotherapy of locally advanced cervical squamous cell carcinoma
}

Zhou-lan Bai ${ }^{1+}$, Yan-yang Wang ${ }^{2 \dagger}$, Hong Zhe ${ }^{2 *}$, Jian-li He${ }^{2}$ and Ping $\mathrm{Hai}^{2}$

\begin{abstract}
Background: The purpose of this study was to investigate whether the excision repair cross-complementation group 1 (ERCC1) mRNA expression could predict treatment response of patients with locally advanced cervical squamous cell carcinoma (LACSCC) who underwent cisplatin-based concurrent chemoradiotherapy (CCCRT).

Methods: A total of sixty LACSCC patients, treated with radical CCCRT from a single institution were evaluated. ERCC1 mRNA expression was determined by quantitative real-time RT-PCR in pre-treatment tumor tissues. The association of ERCC1 status with clinicopathological characteristics (age, histological grade, tumor size, parametrial invasion, lymph node metastasis and FIGO stage) and treatment response were analyzed.

Results: No significant association between ERCC1 mRNA expression and clinicopathological characteristics were observed. Patients with low ERCC1 mRNA level had a significantly higher rate of complete response (86.21\%) than patients with high level of ERCC1 expression (19.36\%; $p<0.001)$. In the logistic regression analysis, low ERCC1 mRNA level retained an independent role in predicting complete response to CCCRT $(P<0.001)$. An ERCC1 expression level of 0.0901 was determined as an optimal cutoff value to identify complete response patients to CCCRT treatment. The sensitivity for detection of a complete response was $81.48 \%$ with a specificity of $96.97 \%$ (area under the curve, 0.893; 95\% confidence interval, 0.804-0.983).

Conclusions: This is the first analysis of the association between ERCC1 mRNA levels and treatment response in patients with LACSCC. Low ERCC1 mRNA level appears to be a highly specific predictor of response to CCCRT in LACSCC.
\end{abstract}

Keywords: Excision repair cross-complementation group 1 (ERCC1), Cervical squamous cell carcinoma, Chemoradiotherapy, Response prediction

\section{Background}

The current standard treatment of locally advanced cervical cancer is cisplatin-based concurrent chemoradiotherapy (CCCRT), followed by brachytherapy [1]. However, individual patients may show quite different patterns of response against CCCRT; some can be cured, but others cannot, and the latter may therefore suffer

\footnotetext{
* Correspondence: nxzh1961@hotmail.com

${ }^{\dagger}$ Equal contributors

${ }^{2}$ Department of Radiation Oncology, General Hospital of Ningxia Medical University, No.804 Shengli Str, Yinchuan, Ningxia 750004, China

Full list of author information is available at the end of the article
}

severe side effects [2]. Identification of biomarkers which predict response to CCCRT will allow patients to avoid toxicity associated with the ineffective therapy.

One of the most promising biomarkers for response prediction is the excision repair cross-complementation group 1 (ERCC1). ERCC1, which is involved in nucleotide excision repair and associated with resistance to cisplatinbased chemotherapy or chemoradiotherapy in various types of cancer [3-10]. Earlier in vitro studies have linked cisplatin resistance to the expression of ERCC1 mRNA in cell lines of cervical cancers [11]. In a murine xenograft model, upregulated ERCC1 expression is associated with 
radioresistance in tumors derived from cervical carcinoma cells [12]. However, the association of ERCC1 and treatment response in clinical setting, especially for cervical squamous cell carcinoma, has not be well documented. The purpose of present study was to evaluate whether the ERCC1 mRNA expression levels could predict the treatment response of patients with locally advanced cervical squamous cell carcinoma (LACSCC) who underwent CCCRT.

\section{Patients and methods}

\section{Patients and samples}

Cervical squamous cell carcinoma tissues and corresponding non-tumorous tissues were obtained with informed consent from sixty consecutive LACSCC patients who underwent biopsy before CCCRT at Ningxia Medical University General Hospital, between June 2009 and June 2010, and frozen in liquid nitrogen until further analysis. Patients had a median age of 53 years (range 36 to 80 years) and no patient received previous radiotherapy or chemotherapy. Histologically, all primary tumors were squamous cell carcinoma. Staging was performed according to International Federation of Gynecology and Obstetrics (FIGO) staging system classification. Clinicopathological characteristics of these patients are listed in Table 1. This study was approved by the ethics committee of our hospital.

\section{Treatment and response}

The pretreatment evaluation included a review of the patient's history, physical examination, performance status, biopsy and gynecologic examination under general anesthesia, chest X-ray, complete blood count, blood chemistry, and abdominal-pelvic magnetic resonance imaging. Cystoscopy and sigmoidoscopy were performed when indicated.

Radiotherapy included external beam radiotherapy up to 50 Gy and low-dose rate brachytherapy, six applications of 6 Gy. Chemotherapy consisted of weekly intravenous cisplatin administration $\left(40 \mathrm{mg} / \mathrm{m}^{2}\right)$ for 5 cycles concomitant with external pelvic radiation. Treatment response was clinically assessed according to the RECIST criteria [13]. We categorized patients into two response groups: the sensitive group and the resistant group. The sensitive group included those patients who achieved a complete response ( $\mathrm{CR}$ as indicated in the RECIST criteria) and remained in remission throughout the follow-up period. The resistant group included patients who had persistent disease (PR, SD and PD as indicated in the RECIST criteria) after treatment or developed a relapse after remission.

\section{RNA Extraction, reverse transcription and quantitative real time RT-PCR (QRT-PCR) assays}

RNA was isolated using the Trizol reagent (Invitrogen, Carlsbad, CA, USA) following the manufacturer's protocol
Table 1 Clinicopathological characteristics of the patients with LACSCC according to the ERCC1 mRNA levels

\begin{tabular}{|c|c|c|c|}
\hline \multirow[t]{2}{*}{ Characteristic } & \multicolumn{2}{|c|}{ ERCC1 mRNA } & \multirow[t]{2}{*}{$P$} \\
\hline & High level & Low level & \\
\hline \multicolumn{4}{|l|}{ Age, y } \\
\hline$\leq 50$ & 14 & 13 & \\
\hline$>50$ & 15 & 18 & 0.622 \\
\hline \multicolumn{4}{|l|}{ Histologic grade } \\
\hline Well and moderately differentiated & 12 & 19 & \\
\hline Poorly differentiated & 17 & 12 & 0.123 \\
\hline \multicolumn{4}{|l|}{ Tumor size, $\mathrm{cm}$} \\
\hline$\leq 4$ & 8 & 12 & \\
\hline$>4$ & 21 & 19 & 0.361 \\
\hline \multicolumn{4}{|l|}{ Parametrial invasion } \\
\hline No & 14 & 15 & \\
\hline Unilateral & 12 & 11 & \\
\hline Bilateral & 3 & 5 & 0.774 \\
\hline \multicolumn{4}{|l|}{ Clinical lymph node involvement } \\
\hline No & 18 & 26 & \\
\hline N1 & 11 & 5 & 0.056 \\
\hline \multicolumn{4}{|l|}{ FIGO stage } \\
\hline$\|$ & 14 & 22 & \\
\hline III & 15 & 9 & 0.073 \\
\hline \multicolumn{4}{|l|}{ Hemoglobin levels at diagnosis, $\mathrm{g} / \mathrm{dL}$} \\
\hline$\leq 11.3$ & 8 & 5 & \\
\hline$>11.3$ & 21 & 26 & 0.282 \\
\hline \multicolumn{4}{|l|}{ Platelets at diagnosis, $\times 10^{9} / \mathrm{L}$} \\
\hline$\leq 320$ & 26 & 24 & \\
\hline$>320$ & 3 & 7 & 0.204 \\
\hline
\end{tabular}

Abbreviations: $L A C S C C$ locally advanced cervical squamous cell carcinomas, ERCC1 excision repair cross-complementation group 1, FIGO International Federation of Gynecology and Obstetrics.

from the cancerous and corresponding non-tumorous tissues. Concentration of total RNA was estimated by a SmarSpec Plus spectrophotometer (BIO-RAD, Hercules, CA,USA) and stored at $-80^{\circ} \mathrm{C}$.

After treatment with DNAfree (Ambion, Austin, TX, USA) to remove chromosomal DNA, complementary DNA (cDNA) was synthesized using SuperScript III Reverse Transcriptase (Invitrogen, Carlsbad, CA, USA) and stored at $-20^{\circ} \mathrm{C}$ until use.

The mRNA expression levels of ERCC1 and beta-actin were measured by quantitative RT-PCR using IQ 5 Multicolor Real-Time PCR Detection Systerm (BIO-RAD, Hercules, CA, USA). The cycling conditions were as follows: $10 \mathrm{~min}$ of an initial denaturation step at $95^{\circ} \mathrm{C}$, followed by 40 cycles of $30 \mathrm{sec}$ at $95^{\circ} \mathrm{C}, 30 \mathrm{sec}$ at $58^{\circ} \mathrm{C}$ and $30 \mathrm{sec}$ at $72^{\circ} \mathrm{C}$. The following primers were used: ERCC1, 
forward: CCTCAGACCTACGCCGAATA; reverse: GCT CACAATGATGCTGTTGG [14]; and beta-actin, forward: TGACGTGGACATCCGCAAAG; Reverse: CTGGAAGGT GGACAGCGAGG.PCR products were scanned, and quantification was performed by the Quantity One program (Bio-Rad, Hercules, CA, USA). The expression of betaactin was used as an internal control. The ERCC1 expression level was normalized to the beta-actin mRNA level using the $2^{-\Delta \Delta \mathrm{Ct}}$ method [15].

\section{Statistical analysis}

The median relative ERCC1 mRNA expression level standardized for beta-actin was selected as cut-off value of high and low level ERCC1 expression. Associations between dichotomized ERCC1 mRNA levels and clinicopathological characteristics were assessed for statistical significance using a chi-square test. Logistic regression models were used to identify independent predictive factors for treatment response. Cut-off values for discrimination of ERCC1 mRNA levels and treatment response were derived from receiver operating curve data (ROC; area under the curve and the 95\% confidence interval). All reported $P$ values are two-sided, and $P$ less than 0.05 was considered statistically significant. SPSS 13.0 (SPSS Inc., Chicago, IL) was used for the statistical analysis.

\section{Results}

ERCC1 mRNA expression levels were successfully measured in sixty patients. The median measured value of ERCC1 mRNA was 23.06 (range, 18.78-25.46). The median relative ERCC1 mRNA expression level standardized for beta-actin was 0.0347 (range, 0.0028-5.4264). Thirty-one (51.67\%) patients were classified as having high level. No significant differences were found in the clinicopathological characteristics between the patients with high ERCC1 mRNA level and those with low level (Table 1).

All patients received the external beam radiotherapy and brachytherapy as indicated in the protocol. For myelosurppression and infectious complications, only 34 (56.67\%) patients received 5 cycles cisplatin-based concurrent chemotherapy. The treatment response was evaluated by CT imaging after treatment completion. Of the 60 patients who entered the study, 33 (55\%) patients had complete response. Patients with low ERCC1 mRNA level had a significantly higher complete response rate $(86.21 \%)$ than patients with high expression levels $(19.36 \%$; $p<0.001)$ (Figure 1). In the logistic regression analysis, only low ERCC1 mRNA level retained an independent role in predicting complete response to CCCRT (Table 2).

ROC analysis was applied to determine an ERCC1 mRNA value that best segregates patients into complete response or non-complete response. An ERCC1 expression level of 0.0901 was determined as an optimal cutoff value to identify complete response to CCCRT treatment. The

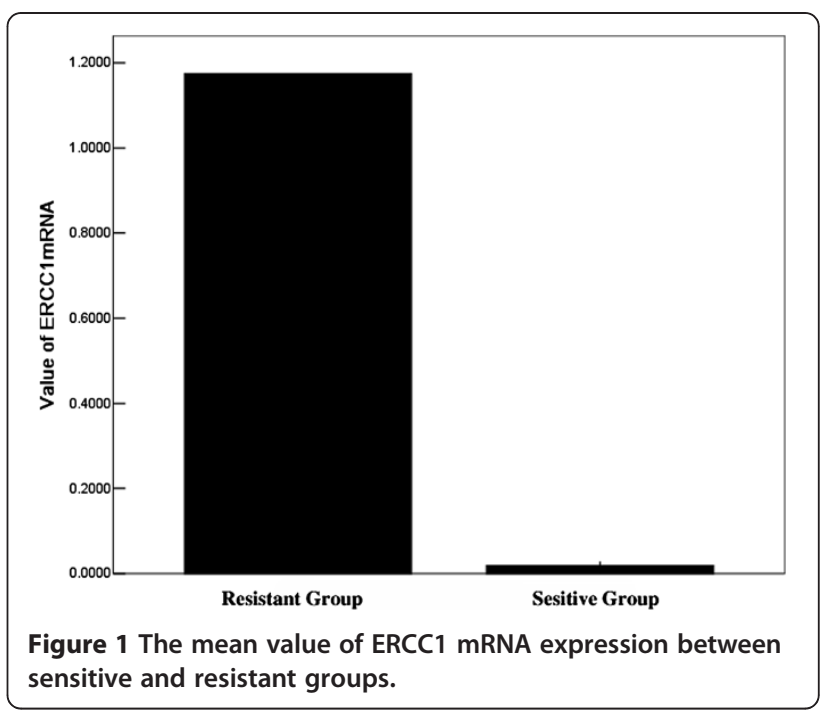

sensitivity for detection of a complete response was $81.48 \%$ with a specificity of $96.97 \%$ (area under the curve, 0.893; 95\% confidence interval, 0.804-0.983) (Figure 2).

\section{Discussions}

The addition of concurrent cisplatin-based chemotherapy to standard radiotherapy could reduce the risk of recurrence and disease-related death rates from locally advanced cervical cancer by as much as $50 \%[16,17]$. However, those without a response will have toxicity helplessly. It would be useful to predict the response and to search for novel approaches for non-responders [18].

ERCC1 plays an important role in recognizing and removing cisplatin-induced DNA adducts and repairs interstrand cross-links in DNA and recombination processes $[19,20]$. Several preclinical and clinical studies have investigated the expression of ERCC1 mRNA and protein in multiple cancer types and have demonstrated a correlation between the ERCC1 expression levels and the treatment response to platinum-based therapy and/or survival outcome [3-10]. These results suggest that ERCC1 expression may assist in selecting patients most likely to benefit from platinum agent-based chemotherapy or chemoradiotherapy.

There are three other studies evaluated the relationship of ERCC1 status and the treatment response or survival of the patients with cervical carcinoma who received radiotherapy or chemoradiotherapy. Liang et al. assessed the ERCC1 expression of 50 patients with cervical squamous cell carcinomas who received cisplatin-based concurrent chemoradiotherapy by immunohistochemistry (IHC) method. They found ERCC1-negative patients had a significantly higher complete response rate than ERCC1positive patients $(P=0.015)$. The 5 -year overall survival (OS) rates for the ERCC1-positive and ERCC1-negative groups were $50.0 \%$ and $85.3 \%$, respectively. For OS, lack of ERCC1 expression was an independent prognostic factor 
Table 2 Results of logistic regression analysis for clinical factors and response to CCCRT

\begin{tabular}{lcccccc}
\hline & B & SE & Wald & P value & OR & 95\% Cl for OR \\
\hline Age & -0.104 & 0.064 & 2.599 & 0.107 & 0.902 & $0.795-1.023$ \\
Histologic grade & -0.450 & 1.090 & 0.171 & 0.680 & 0.638 & $0.075-5.399$ \\
Tumor size & 2.908 & 1.567 & 3.445 & 0.063 & 18.315 & $0.850-394.766$ \\
Parametrial invasion & 2.773 & 1.878 & 2.180 & 0.140 & 16.011 & $0.403-635.705$ \\
Lymph node status & -0.274 & 1.060 & 0.067 & 0.796 & 0.760 & $0.095-6.074$ \\
FIGO stage & 2.471 & 1.797 & 1.891 & 0.169 & 11.836 & $0.349-400.843$ \\
Hemoglobin levels at diagnosis & -0.326 & 1.252 & 0.068 & 0.795 & 0.722 & $0.062-8.398$ \\
Platelets at diagnosis & -0.166 & 1.309 & 0.016 & 0.899 & 0.847 & $0.065-11.013$ \\
ERCC1 mRNA status & 5.003 & 1.408 & 12.624 & 0.000 & 148.869 & $9.424-2351.736$ \\
Chemotherapy cycles & -0.932 & 1.073 & 0.755 & 0.385 & 0.394 & $0.048-3.225$ \\
\hline
\end{tabular}

Abbreviations: CCCRT cisplatin-based concurrent chemoradiotherapy, $B$ regression coefficient, SE standard error, Wald Wald value, OR odds ratio, CI confidence interval, FIGO International Federation of Gynecology and Obstetrics, ERCC1 excision repair cross-complementation group 1.

[21]. Doll et al. evaluated the association of ERCC1 expression, using both mRNA and protein expression analysis, with clinical outcome in cervical cancer patients treated with radical radiotherapy. ERCC1 mRNA level was determined by real-time PCR, and ERCC1 protein expression (FL297, 8F1) was measured using quantitative IHC. ERCC1 protein expression levels using both FL297 and 8F1 antibodies were determined for 112 patients; mRNA analysis was performed in 32 patients. In the 112 patients, 99 patients were squamous cell carcinomas, and 33 patients were adenocarcinomas. Low ERCC1 mRNA expression status was associated with worse OS $(\mathrm{p}=0.046)$. ERCC1 protein expression using the FL297 antibody, but not the 8F1 antibody, was significantly associated with both OS $(p=0.002)$ [22]. Hasegawa et al. analyzed the ERCC1 expression of 36 patients with cervical adenocarcinoma by IHC method. Among the 25 patients who received cisplatin-based chemotherapy or chemoradiotherapy with cisplatin, those with high ERCC1 expression experienced significantly worse disease-free survival than those with low ERCC1 expression $(P=0.002)$. Moreover, univariate and multivariate analyses revealed that high ERCC1 expression was an independent prognostic factor in patients receiving cisplatin-based chemotherapy or chemoradiotherapy with cisplatin [23]. Our study is the first analysis of the association between ERCC1 mRNA expression and treatment response in patients with cervical squamous cell carcinomas who received radical cisplatinbased concurrent chemoradiotherapy. Sixty patients were evaluated in this study, which is the largest number among these studies. We firstly found that cervical squamous cell carcinomas patients with low ERCC1 mRNA level had a significantly higher rate of complete response than patients with high level of ERCC1 expression $(P<0.001)$. In the logistic regression analysis, low ERCC1 mRNA level retained an independent role in predicting complete response to CCCRT $(P<0.001)$.
Although the results of our study are similar to Liang's and Hasegawa's study, which are opposite to Doll's study. The first reason of these differences is the histology type of enrolled patients was different. Squamous cell carcinoma comprises around $85 \%$ to $90 \%$ of uterine cervical cancer $[24,25]$. It has different biology behavior and treatment response when compared with adenocacinoma $[2,26]$. In Doll's study, there are $11 \%$ patients with cervical adenocarcinoma. The second reason is that the treatment method was different between two studies. In Doll's study, they used radiation alone. In fact, ERCC1 expression and the response of chemotherapy also have interaction [10].

There are some shortages in this study. Firstly, we did not perform IHC. High ERCC1 mRNA only signifies ERCC1 DNA transcription and does not necessarily reflect

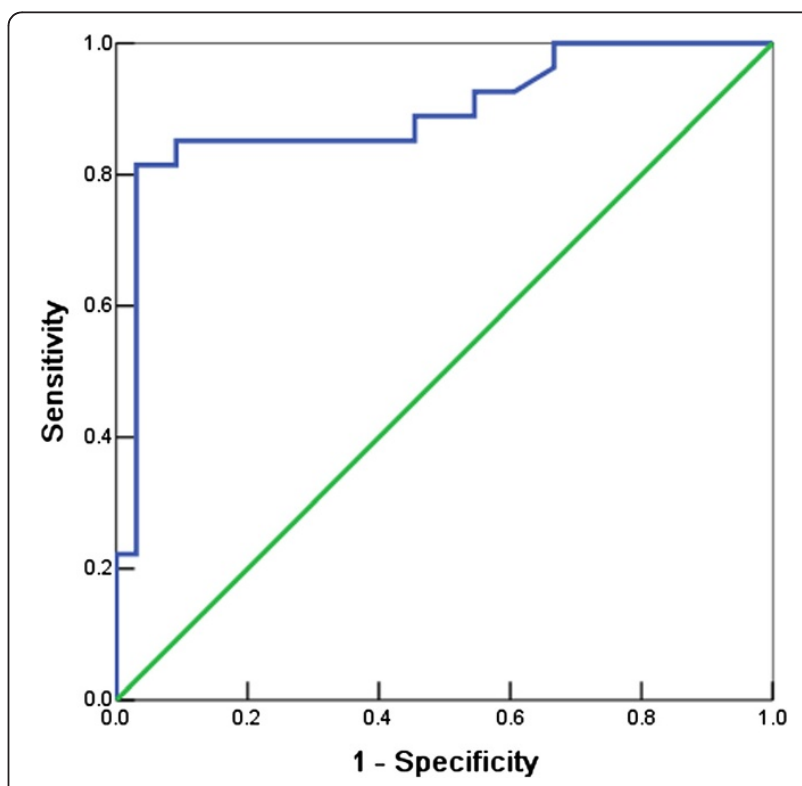

Figure 2 ROC curve depicting sensitivity and specificity of ERCC1 mRNA levels in predicting complete response of CCCRT. 
the production of functional ERCC1 protein, which could be assessed by IHC. We will evaluate the ERCC1 protein expression and the treatment response of LACSCC in further study. Secondly, the number of patients was small. We need do further research to validate the results in large number patients. Lastly, due to the short follow-up time, the association of ERCC1 mRNA levels and survival was not performed in present study at this point.

\section{Conclusions}

This is the first study to evaluate the relationship of ERCC1 mRNA levels and complete response of LACSCC who underwent CCCRT. We have shown that ERCC1 expression patterns in pretreatment cancerous specimens can be effectively used to predict response to CCCRT. These results suggest that ERCC1 expression may assist in selecting patients most likely to benefit from CCCRT. Further investigation is required to determine whether these assays are sufficiently reliable to use routinely as a basis to select specific patient treatments.

\section{Competing interests}

The authors declare that they have no competing interests.

\section{Authors' contributions}

ZL Bai and YY Wang participated in acquiring clinical and laboratory data, data analysis and interpretation, acquiring clinical samples, follow-up clinical information and final writing of the manuscript. H Zhe, JL He and P Hai participated in acquiring clinical and laboratory data, data analysis and data interpretation and drafted the manuscript. All authors read and approved the final manuscript.

\section{Author details}

${ }^{1}$ Graduate School, Ningxia Medical University, No.1160 Shengli Str, Yinchuan, Ningxia 750004, China. ${ }^{2}$ Department of Radiation Oncology, General Hospital of Ningxia Medical University, No.804 Shengli Str, Yinchuan, Ningxia 750004, China.

Received: 13 June 2012 Accepted: 17 December 2012

Published: 23 December 2012

\section{References}

1. Haie-Meder C, Morice P, Castiglione M, ESMO Guidelines Working Group: Cervical cancer: ESMO clinical recommendations for diagnosis, treatment and follow-up. Ann Oncol 2009, 20(Suppl 4):iv27-iv28.

2. Quinn MA, Benedet JL, Odicino F, Maisonneuve P, Beller U, Creasman WT, Heintz AP, Ngan HY, Pecorelli S: Carcinoma of the cervix uteri. FIGO 26th Annual Report on the Results of Treatment in Gynecological Cancer. Int J Gynaecol Obstet 2006, 95(Suppl 1):S43-S103.

3. Olaussen KA, Dunant A, Fouret P, Brambilla E, André F, Haddad V, Taranchon E, Filipits M, Pirker R, Popper HH, Stahel R, Sabatier L, Pignon JP, Tursz T, Le Chevalier T, Soria JC, IALT Bio Investigators: DNA repair by ERCC1 in non-small-cell lung cancer and cisplatin-based adjuvant chemotherapy. N Engl J Med 2006, 355(10):983-991.

4. Metzger R, Leichman CG, Danenberg KD, Danenberg PV, Lenz HJ, Hayashi K, Groshen S, Salonga D, Cohen H, Laine L, Crookes P, Silberman H, Baranda J, Konda B, Leichman L: ERCC1 mRNA levels complement thymidylate synthase mRNA levels in predicting response and survival for gastric cancer patients receiving combination cisplatin and fluorouracil chemotherapy. J Clin Oncol 1998, 16(1):309-316.

5. Kim MK, Cho KJ, Kwon GY, Park SI, Kim YH, Kim JH, Song HY, Shin JH, Jung $H Y$, Lee GH, Choi KD, Kim SB: ERCC1 predicting chemoradiation resistance and poor outcome in oesophageal cancer. Eur J Cancer 2008, 44(1):54-60.

6. Bellmunt J, Paz-Ares L, Cuello M, Cecere FL, Albiol S, Guillem V, Gallardo E, Carles J, Mendez P, de la Cruz JJ, Taron M, Rosell R, Baselga J, Spanish
Oncology Genitourinary Group: Gene expression of ERCC1 as a novel prognostic marker in advanced bladder cancer patients receiving cisplatin-based chemotherapy. Ann Oncol 2007, 18(3):522-528.

7. Scheil-Bertram S, Tylus-Schaaf P, du Bois A, Harter P, Oppitz M, Ewald-Riegler N, Fisseler-Eckhoff A: Excision repair cross-complementation group 1 protein overexpression as a predictor of poor survival for high-grade serous ovarian adenocarcinoma. Gynecol Oncol 2010, 119(2):325-331.

8. Handra-Luca A, Hernandez J, Mountzios G, Taranchon E, Lacau-St-Guily J, Soria JC, Fouret P: Excision repair cross complementation group 1 immunohistochemical expression predicts objective response and cancer-specific survival in patients treated by Cisplatin-based induction chemotherapy for locally advanced head and neck squamous cell carcinoma. Clin Cancer Res 2007, 13(13):3855-3859.

9. Warnecke-Eberz U, Metzger R, Miyazono F, Baldus SE, Neiss S, Brabender J, Schaefer H, Doerfler W, Bollschweiler E, Dienes HP, Mueller RP, Danenberg PV, Hoelscher AH, Schneider PM: High specificity of quantitative excision repair cross-complementing 1 messenger RNA expression for prediction of minor histopathological response to neoadjuvant radiochemotherapy in esophageal cancer. Clin Cancer Res 2004, 10(11):3794-3799.

10. Metzger R, Bollschweiler E, Hölscher AH, Warnecke-Eberz U: ERCC1: impact in multimodality treatment of upper gastrointestinal cancer. Future Oncol 2010, 6(11):1735-1749.

11. Britten RA, Liu D, Tessier A, Hutchison MJ, Murray D: ERCC1 expression as a molecular marker of cisplatin resistance in human cervical tumor cells. Int J Cancer 2000, 89(5):453-457.

12. Hampson L, El Hady ES, Moore JV, Kitchener H, Hampson IN: The HPV16 E6 and E7 proteins and the radiation resistance of cervical carcinoma. FASEB J 2001, 15(8): 1445-1447.

13. Therasse P, Arbuck SG, Eisenhauer EA, Wanders J, Kaplan RS, Rubinstein L, Verweij J, Van Glabbeke M, van Oosterom AT, Christian MC, Gwyther SG: New guidelines to evaluate the response to treatment in solid tumors. European Organization for Research and Treatment of Cancer, National Cancer Institute of the United States, National Cancer Institute of Canada. J Natl Cancer Inst 2000, 92(3):205-216.

14. Sonnenberg M, van der Kuip H, Haubeis S, Fritz P, Schroth W, Friedel G, Simon W, Mürdter TE, Aulitzky WE: Highly variable response to cytotoxic chemotherapy in carcinoma-associated fibroblasts (CAFs) from lung and breast. BMC Cancer 2008, 8:364.

15. Livak KJ, Schmittgen TD: Analysis of relative gene expression data using real-time quantitative PCR and the 2(-Delta Delta $C(T))$ Method. Methods 2001, 25(4):402-408.

16. Eifel PJ: Concurrent chemotherapy and radiation: a major advance for women with cervical cancer. J Clin Oncol 1999, 17(5):1334-1335.

17. Green JA, Kirwan JM, Tierney JF, Symonds P, Fresco L, Collingwood M, Williams CJ: Survival and recurrence after concomitant chemotherapy and radiotherapy for cancer of the uterine cervix: a systematic review and meta-analysis. Lancet 2001, 358(9284):781-786.

18. Klopp AH, Eifel PJ: Biological predictors of cervical cancer response to radiation therapy. Semin Radiat Oncol 2012, 22(2):143-150.

19. Sancar A: Mechanisms of DNA excision repair. Science 1994, 266(5193):1954-1956.

20. Reed E: Platinum-DNA adduct, nucleotide excision repair and platinum based anti-cancer chemotherapy. Cancer Treat Rev 1998, 24(5):331-344.

21. Liang ZL, Song EK, Ko YB, Lee NR, Yhim HY, Noh HT, Yun HJ, Suh KS, Jo DY, Kim S, Kim JS, Kim JM, Lee HJ: Excision repair cross-complementation group 1 expression predicts response and survival in locally advanced cervical carcinoma patients treated with concurrent chemoradiotherapy. Histopathology 2011, 59(3):564-567.

22. Doll CM, Prystajecky M, Eliasziw M, Klimowicz AC, Petrillo SK, Craighead PS, Hao D, Diaz R, Lees-Miller SP, Magliocco AM: Low ERCC1 mRNA and protein expression are associated with worse survival in cervical cancer patients treated with radiation alone. Radiother Oncol 2010, 97(2):352-359.

23. Hasegawa K, Kato R, Torii Y, Ichikawa R, Oe S, Udagawa Y: The relationship between ERCC1 expression and clinical outcome in patients with FIGO stage I to stage II uterine cervical adenocarcinoma. Int J Gynecol Cancer 2011, 21(8):1479-1485.

24. Smith HO, Tiffany MF, Qualls CR, Key CR: The rising incidence of adenocarcinoma relative to squamous cell carcinoma of the uterine cervix in the United States-a 24-year population-based study. Gynecol Oncol 2000, 78(2):97-105. 
25. Chan PG, Sung HY, Sawaya GF: Changes in cervical cancer incidence after three decades of screening US women less than 30 years old. Obstet Gynecol 2003, 102(4):765-773.

26. Yeasmin S, Nakayama K, Rahman MT, Rahman M, Ishikawa M, Katagiri A, lida K, Nakayama N, Otuski Y, Kobayashi H, Nakayama S, Miyazaki K: Biological and clinical significance of NAC1 expression in cervical carcinomas: a comparative study between squamous cell carcinomas and adenocarcinomas/adenosquamous carcinomas. Hum Pathol 2012, 43(4):506-519.

doi:10.1186/1748-717X-7-221

Cite this article as: Bai et al: ERCC1 mRNA levels can predict the response to cisplatin-based concurrent chemoradiotherapy of locally advanced cervical squamous cell carcinoma. Radiation Oncology 2012 7:221.

\section{Submit your next manuscript to BioMed Central and take full advantage of:}

- Convenient online submission

- Thorough peer review

- No space constraints or color figure charges

- Immediate publication on acceptance

- Inclusion in PubMed, CAS, Scopus and Google Scholar

- Research which is freely available for redistribution 